\title{
STRESSES CALCULATION FOR A VERTICAL STORAGE TANK: MEMBRANE THEORY VS. FINITE ELEMENT METHOD
}

\author{
Maria Tănase ${ }^{1}$ \\ ${ }^{1}$ Universitatea Petrol-Gaze din Ploieşti, România \\ e-mail: maria.tanase@upg-ploiesti.ro
}

\section{DOI: 10.51865/JPGT.2021.02.01}

\begin{abstract}
The objective of this paper is to calculate the stresses in the cylindrical walls of a vertical storage tank.

The stresses state was determined both with membrane theory analysis and with finite element method (FEM), in order to make a comparison between the two methods and thus to validate the numerical method.
\end{abstract}

Keywords: tank, membrane theory, finite element method, stresses.

\section{INTRODUCTION}

Liquid storage tanks are important very important components in oil industry, but also in many other fields of activity. They are built in a multitude of shapes and sizes and can be vertical or horizontal, aboveground, semi- underground or underground. The most commonly used are the cylindrical vertical steel tanks, ground-supported because they are simply in design, efficient in resisting primary hydrostatic pressure and can be easily constructed [1].

The shell of the tanks should be designed after four limit states: plastic limit, cyclic plasticity, buckling and fatigue [2]. In this study, the calculations will be made for the plastic limit.

In accordance with the standard, the first important step in tank design is to establish the consequence class, in function of tank content and its size.

In EN 1993-4-2:2007 [4] is specified that for tanks in consequence class 1 should be used membrane theory with factors and simplified expressions for local bending. For the second consequence class, can be used the membrane theory as long as the load is axisymmetric, but a numerical analysis such as finite element method (FEM) is also suggested. For the consequence class 3, a validated analysis like FEM is imposed by the standard.

\section{THE CHARACTERISTICS OF THE ANALYZED STRUCTURE}

In the present work is analyzed an aboveground crude oil tank with capacity of $500 \mathrm{~m}^{3}$ covered with mineral wool insulation of $50 \mathrm{~mm}$ thickness (insulation density is $\gamma_{\text {ins }}=$ $\left.0.98 \mathrm{kN} / \mathrm{m}^{3}\right)$. 
The shell, bottom, roof plates of the tank are made of steel S235 J2 with the following properties: yield strength $f_{y}=235 \mathrm{~N} / \mathrm{mm}^{2}$, tensile strength $f_{u}=360 \mathrm{~N} / \mathrm{mm}^{2}$ and volume weight $\gamma_{s}=78.5 \mathrm{kN} / \mathrm{m}^{3}$.

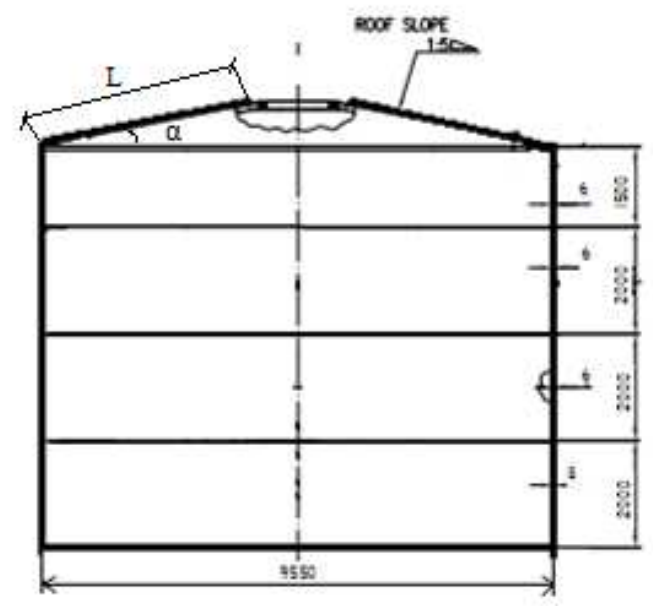

Figure 1. Tank geometry.

The outer diameter is $D_{e}=9550 \mathrm{~mm}$ and the total height of the cylinder walls is $H=$ $7500 \mathrm{~mm}$. The cylindrical part of the tank consists of four courses with different wall thicknesses, decreasing from the bottom to the superior part of the shell, as shown in Figure 1.

\section{THE LOADS ACTING ON TANK}

The calculation was made by considering the self-weight, hydrostatic pressure, wind loads and snow loads. Other loads that can act on tanks, for example thermal loads, accidental loads and seismic loads were not considered.

\section{Self-weight}

The weight of the shell was calculated by multiplying the density of the steel with the volume of the shell, resulting $W_{\text {shell }}=115.404 \mathrm{kN}$.

The volume of the shell was calculated as $V_{\text {shell }}=1.47 \mathrm{~m}^{3}$.

The self-weight of the roof was calculated by multiplying the volume of the roof plates with the density of the steel and it was obtained $W_{\text {roof }}=34.406 \mathrm{kN}$.

The roof volume is $V_{\text {roof }}=0.438 \mathrm{~m}^{3}$.

The weight of the insulation on the shell and on the roof was calculated in the same way and resulted as $W_{\text {ins_shell }}=68.75 \mathrm{kN}$ and $W_{\text {ins_roof }}=3.582 \mathrm{kN}$.

The hydrostatic pressure was calculated with the formula (1) given by EN 1991-4: 2006 [3].

$$
P(z)=\gamma_{l i q} \cdot(H-z)
$$

The density of the oil was set to $715.4 \mathrm{~kg} / \mathrm{m}^{3}$. 
The maximum liquid level is considered at $7.5 \mathrm{~m}$ (the top of the shell), therefore the hydrostatic pressure acts only on the shell.

The maximum hydrostatic pressure appears at the bottom of the shell and has the value $5.258 \cdot 10^{4} \mathrm{~Pa}$.

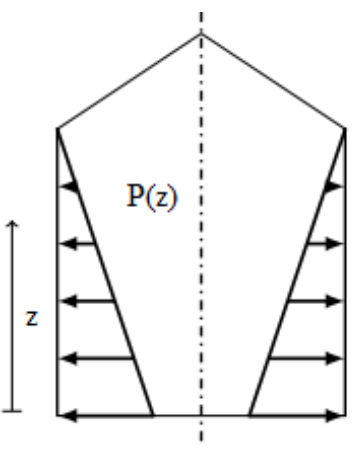

a) Hydrostatic pressure

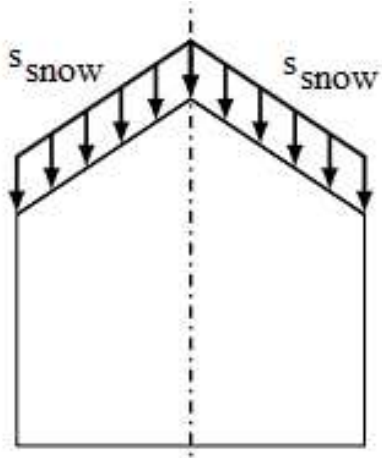

b) Snow loads

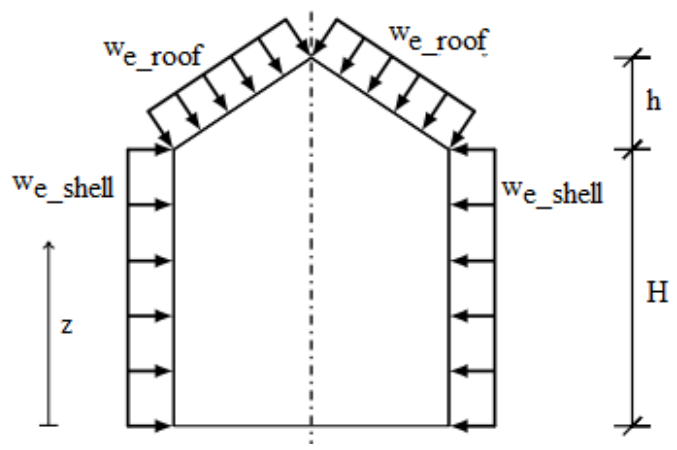

c) Wind loads

Figure 2. Loads representation [2].

The wind loads for shell and roof were calculated according to EN 1991-1-4: 2006, and were obtained as: $w_{e_{-} \text {shell }}=-546.85 \mathrm{~Pa}$ and $w_{e_{-} \text {roof }}=-253.4 \mathrm{~Pa}$.

The snow load acting on the roof was calculated according to EN 1991-1-3:2005 and it resulted as $s_{\text {snow }}=600 \mathrm{~Pa}$.

\section{DETERMINATION OF THE STRESS STATE WITH FINITE ELEMENT METHOD}

The numerical analysis was made in Ansys Workbench. The tank shell was firstly modeled as a solid from four different sections. The solid was then converted into a shell model using the midsurfaces of the sections as can be seen in figure 3 . 

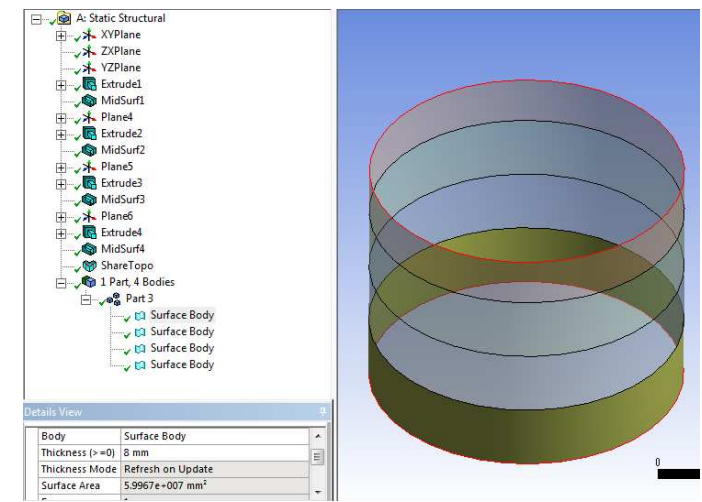

a) first course $(t=8 \mathrm{~mm})$
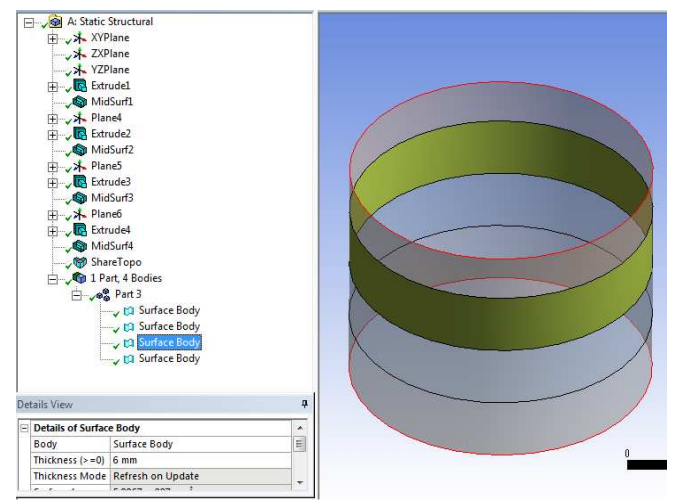

c) third course $(t=6 \mathrm{~mm})$
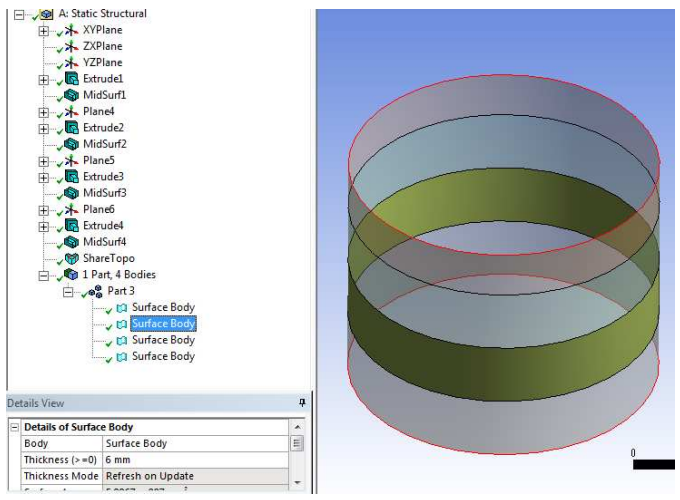

b) second course $(t=6 \mathrm{~mm})$
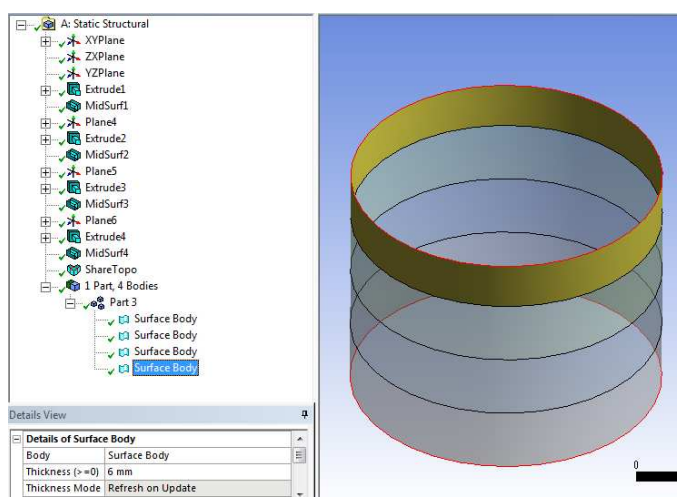

d) fourth course $(t=6 \mathrm{~mm})$

Figure 3. Model of the tank with stepped wall thickness.

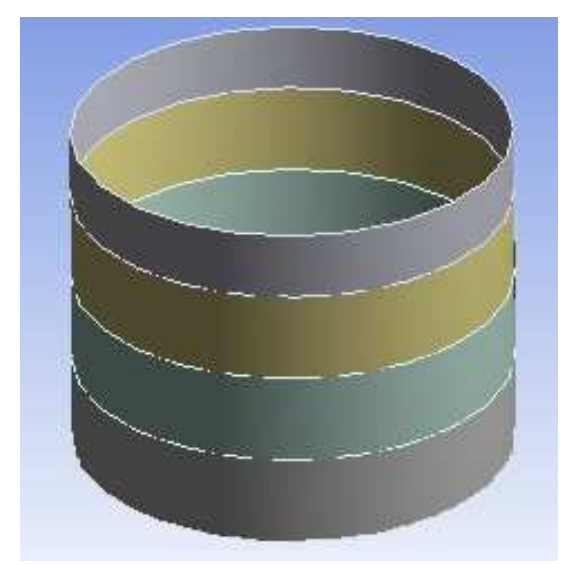

a)

The geometric model

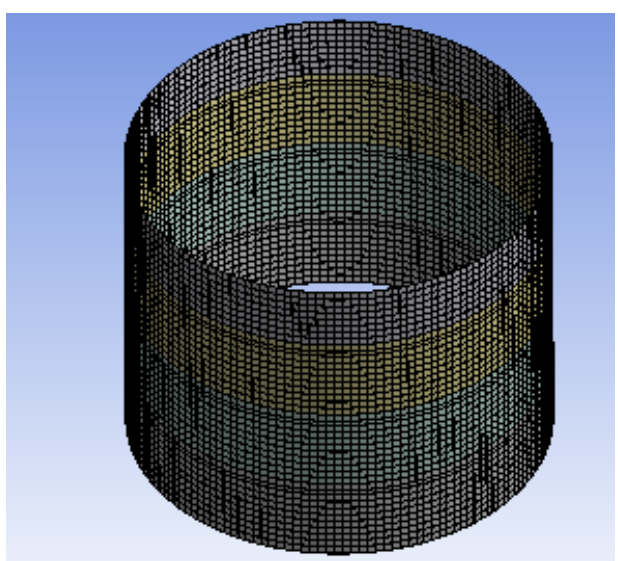

b)

The finite elements model

Figure 4. The model used in numerical analysis.

Since only the shell was used in numerical analysis, it was necessary to impose proper boundary conditions. The boundary conditions given by EN 1993-1-6:2007 for anchored tanks with roofs were: zero displacement in radial direction at the top (BC2f) and zero displacement in radial and axial direction and the bottom (BC1f) [5] - figure 5. 


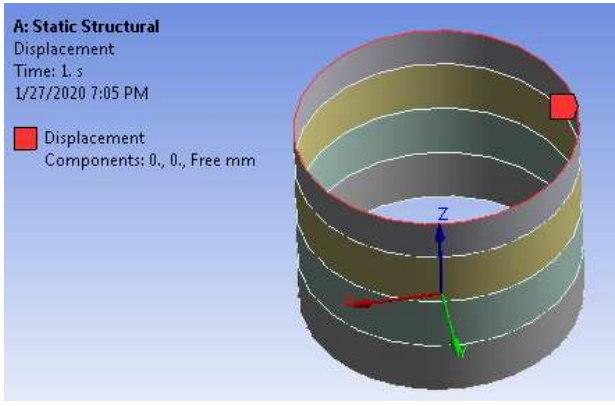

a) tank top

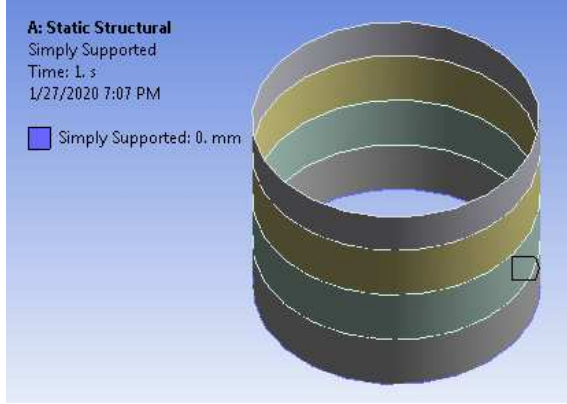

b) tank bottom

Figure 5. The boundary conditions.

The load from the roof was represented as a line pressure with a magnitude of 3.332 $\mathrm{N} / \mathrm{mm}$, in the negative axial direction, at the top edge (figure 6c) and it represents the resulting load of self-weight of the roof, wind load and snow load acting on the roof.

The loads introduced are represented in figure 6.

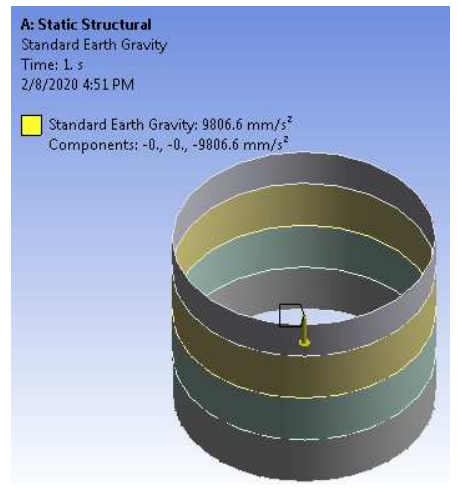

a) shell self-weight

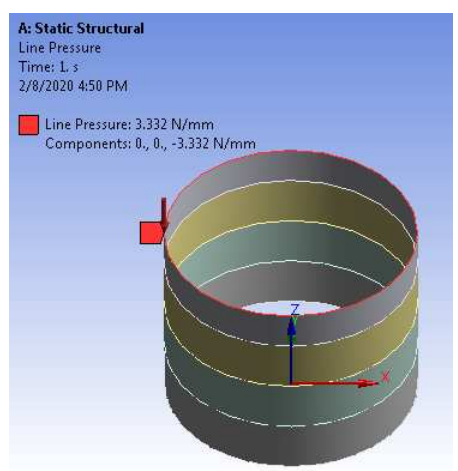

c) the load acting on the roof

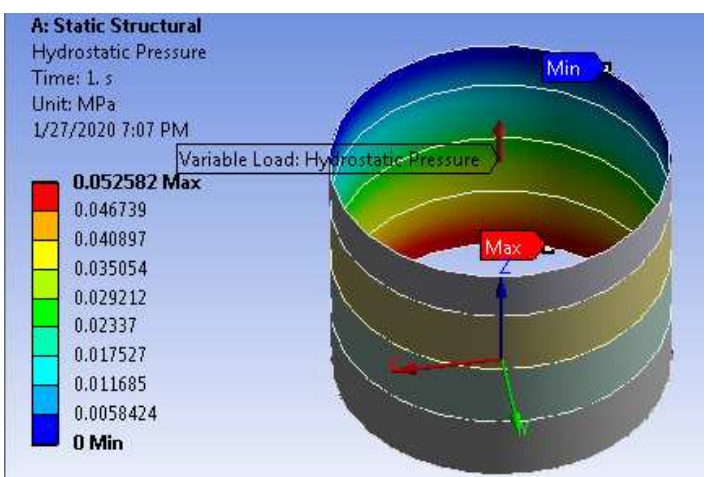

b) the hydrostatic pressure

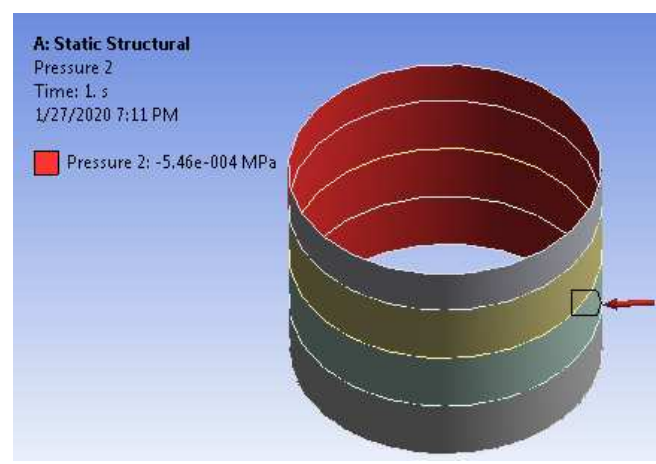

d) the wind load on the shell

Figure 6. The loads.

As can be seen in figure 7, the variation of the hydrostatic pressure on the shell height in numerical analysis is similar to the analytical calculation. 


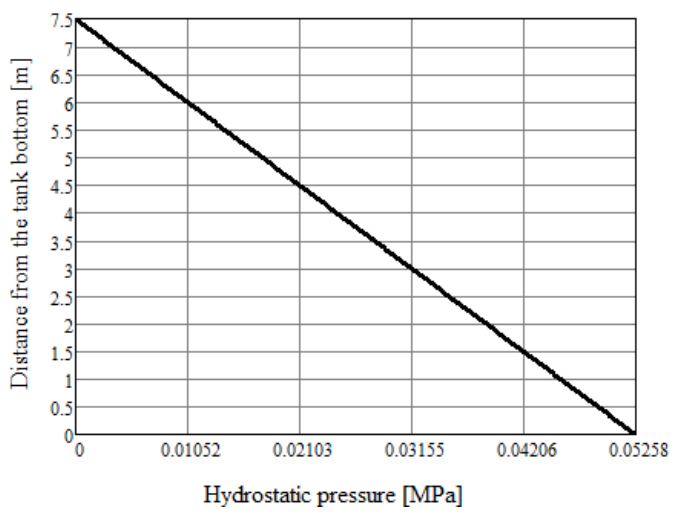

a) analytical calculation

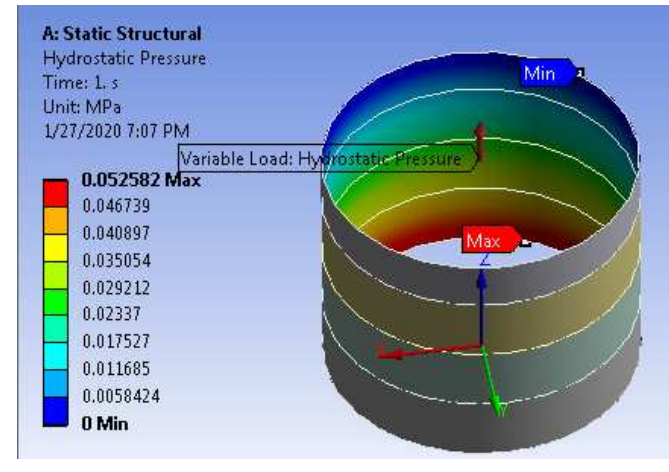

b) finite element analysis

Figure 7. The hydrostatic pressure variation on the shell.

\section{DETERMINATION OF THE STRESS STATE WITH MEMBRANE THEORY}

Considering the loads acting on the roof presented before, the load per unit length acting on the superior circumference of the shell was calculated as [2]:

$$
F_{\text {roof }, x}=\frac{1}{2} \cdot\left(\frac{W_{\text {roof }}+W_{\text {ins_roof }}}{A_{\text {roof }}}\right) \cdot L+\frac{s_{\text {snow }} \cdot L}{2}+\frac{w_{e_{-} \text {roof }} \cdot L \cdot \cos \alpha}{2}
$$

where $A_{\text {roof }}=73.05 \mathrm{~m}^{2}$ is the roof area, $L$ and $\alpha$ refer to roof dimension - see figure 1 .

The variation of the forces acting on the sides of the shell element (forces per unit length) with the shell height is given by the expressions [2]:

$$
\begin{aligned}
& N_{x}(z)=-F_{\text {roof }, x}-\frac{W_{\text {shell }}}{\pi D_{m}} \cdot\left(\frac{H-z}{H}\right) \\
& N_{\theta}(z)=\frac{P(z) D_{i}-w_{e_{-} \text {shell }} D_{e}}{2}
\end{aligned}
$$

where $D_{m}, D_{i}, D_{e}$ are the mean, inside respectively outside diameters of the shell.

The axial, respectively circumferential stresses are:

$$
\begin{aligned}
& \sigma_{x}(z)=\frac{N_{x}(z)}{t} \\
& \sigma_{\theta}(z)=\frac{N_{\theta}(z)}{t}
\end{aligned}
$$

where $t$ is the shell thickness at the height $z$.

The equivalent stress in a point is calculated as [5]:

$$
\sigma_{e c h}(z)=\sqrt{\sigma_{x}(z)^{2}+\sigma_{\theta}(z)^{2}-\sigma_{x}(z) \sigma_{\theta}(z)}
$$




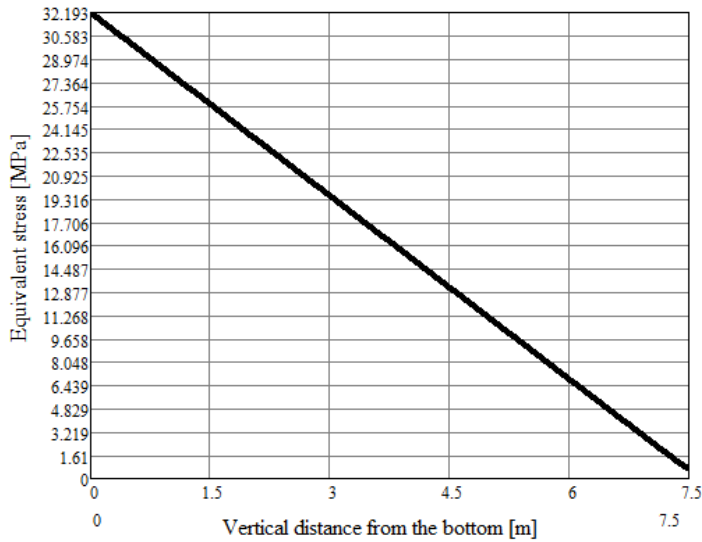

a) Analytical calculation

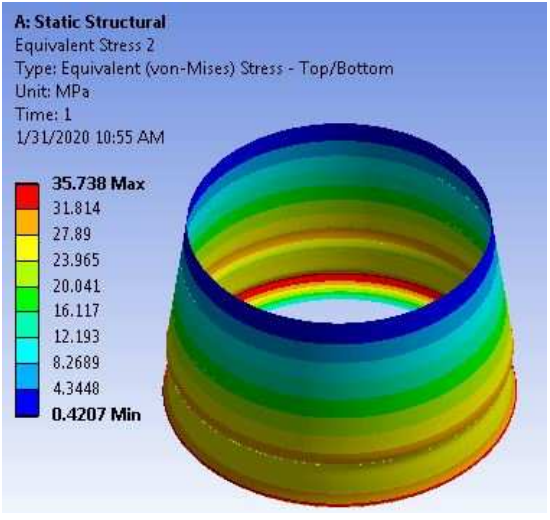

b) Finite element analysis

Figure 8. Equivalent stresses variation.

In figure 8 is represented the comparison between the variation of the equivalent stress obtained analytical and numerical. The maximum equivalent stress appears at the shell bottom. The results obtained are very close - the maximum equivalent stress obtained analytical was $\sigma_{e c h, \max }^{a n}=32.193 \mathrm{MPa}$ and the maximum equivalent stress obtained numerical was $\sigma_{\text {ech, } \max }^{\text {num }}=35.73 \mathrm{MPa}$. The difference between the analytical and numerical values is only $9.89 \%$.

\section{CONCLUSIONS}

In the present work it was determined analytical and numerical the stress distribution for a tank with a capacity of $500 \mathrm{~m}^{3}$ used to store crude oil, taking into account the selfweight, the hydrostatic pressure, the wind and the snow loads. The results showed a very good agreement between the values of the maximum equivalent stress obtained with the two methods (a difference of only 9.89\%).

Since the finite element method is a very important tool in tank design, a valid method imposed or suggested by the standards for all the consequence classes, it is very important to validate it in order to be used for tanks of different capacities and with different content.

\section{REFERENCES}

[1] Matko G., Design of liquid-storage tank: results of software modeling vs calculations according to Eurocode, Electronic Journal of the Faculty of Civil Engineering Osijek-e-Gfos, vol. 8 no. 15, 2017.

[2] Pluto M., Tank Shell Design According to Eurocodes and Evaluation of Calculation Methods, Student thesis, 2018.

[3] *** EN 1991-4:2006, Actions on structures, Silos and tanks.

[4] *** EN 1993-4-2:2008, Design of steel structures, Tanks. 
[5] *** EN 1993-1-6, Design of steel structures. Strength and stability of shell Structures.

[6] *** EN 1991-1-4:2005. Actions on structures - Part 1-4: General actions - Wind actions.

[7] *** EN 1991-1-3:2003, Actions on structures - Part 1-3: General actions - Snow loads. 